\title{
Sociodemographic Characteristics of Communities Served by Retail Clinics
}

\author{
Rena Rudavsky, BS, and Ateev Mehrotra, MD, MPH
}

Purpose: As a rapidly growing new health care delivery model in the United States, retail clinics have been the subject of much debate and controversy. Located physically within a retail store, retail clinics provide simple acute and preventive services for a fixed price and without an appointment. Some hope that retail clinics can be a new safety-net provider for the poor and those without a primary care physician. To better understand the potential for retail clinics to achieve this goal, we describe the sociodemographic characteristics of the communities in which they operate.

Methods: We created an inventory of all retail clinics in the United States and determined the proportion that are in a health professional shortage area (HPSA). We defined each retail clinic's catchment area as all census blocks that were less than a 5-minute driving distance from the clinic. We compared the sociodemographic characteristics of the population within and outside of these retail clinic catchment areas.

Results: Of the 982 clinics in 32 states, $88.4 \%$ were in an urban area and $12.5 \%$ were in an HPSA (20.9\% of the US population lives within an HPSA). Compared with the rest of the urban population, the population living within a retail clinic catchment area has a higher median household income $\mathbf{( \$ 5 2 , 8 4 9}$ vs $\$ \mathbf{4 6 , 0 8 0})$, is better educated $(32.6 \%$ vs $24.9 \%$ with a college degree), and is as likely to be uninsured (17.7\% vs $17.0 \%)$. In a multivariate model, the census block's median household income had the strongest association with whether the census block was in a retail clinic catchment area (odds ratio, 3.63; 95\% CI, 3.26-4.05; median income, $\geq \$ 54,779$ vs $<\$ 30,781$, respectively).

Conclusions: We found that relatively few retail clinics are located in HPSAs and that, compared with the rest of the urban population, the population living in close proximity to a retail clinic has a higher income. (J Am Board Fam Med 2010;23:42-48.)

Offering a novel method of health care delivery, retail clinics have garnered significant interest from patients, politicians, physicians, and health plans. They are called retail clinics because they are physically located in retail stores like grocery stores, drugstores, or "big box" stores such as Wal-Mart. Retail clinics provide walk-in care for a limited

This article was externally peer reviewed.

Submitted 20 February 2009; revised 12 May 2009; accepted 20 May 2009.

From RAND Health, Pittsburgh, PA (RR) and Washington, DC (AM); and the University of Pittsburgh School of Medicine (AM), Pittsburgh, PA.

Funding: This work was supported by a grant (08-1136) from the California Health Care Foundation and a career development award from the National Center for Research Resources, a component of the National Institutes of Health. The funders had no role in the design and conduct of the study; the collection, management, analysis, and interpretation of the data; or the preparation, review, or approval of the manuscript.

Conflict of interest: none declared.

Corresponding author: Ateev Mehrotra, MD, MPH, General Internal Medicine, University of Pittsburgh School of Medicine, 230 McKee Place, Suite 600, Pittsburgh, PA 15213 (E-mail: mehrotra@rand.org). number of acute illnesses and preventative care services for a fixed price. Visits are usually covered by most health insurance plans. ${ }^{1}$ Generally staffed by nurse practitioners, retail clinics focus on patient convenience by requiring no appointment and offering night and weekend hours. The number of retail clinics has increased rapidly, and it is estimated that there were 3 million patient visits to retail clinics in $2008 .^{2}$

As the number of retail clinics has increased, several physician associations have raised concerns about the retail clinic model. They worry that retail clinics can possibly increase fragmentation of care, provide inferior care, and adversely impact the delivery of preventative care. ${ }^{3-9}$ Most retail clinics are owned by for-profit drugstore chains. Some have worried that, in an effort to increase pharmacy sales, retail clinic providers will overprescribe medications. ${ }^{4,5}$ However, policymakers, including California Governor Arnold Schwarzenegger, ${ }^{10}$ Pennsylvania Governor Ed Rendell, ${ }^{11}$ and Senator John McCain, ${ }^{12}$ have supported the growth of retail clin- 
ics and included them in their health reform proposals. Potential cited benefits of clinics include improving access to care and providing affordable care for the poor and underserved. ${ }^{13,14}$

Despite the interest and controversy generated by retail clinics, there has been little empirical evaluation of their impact. ${ }^{1,15-21}$ The goals of this study were to describe the location of retail clinics, determine whether they are disproportionately located in areas with a scarcity of health providers, and describe the sociodemographic characteristics of the population that lives close to a retail clinic.

\section{Methods}

\section{Inventory of Retail Clinics}

We compiled a list of retail clinic companies based on several sources: recent industry reports, analysis from a clinic consulting company (merchantmedicine.com), and general web searches. ${ }^{22,23}$ To our knowledge there have been no hard definitions of retail clinics in previous literature. We therefore chose to define retail clinics based on the following 3 criteria: (1) location within a retail store, (2) staffing by nurse practitioners or physician assistants, and (3) a limited menu of services with specified fixed prices. We did include some companies whose clinics did not satisfy all these criteria but embodied the character of the model. For example, we included QuickHealth clinics, which are located in retail stores such as Wal-Mart and use a menu of services but are staffed by physicians. We chose to include 2 clinic operators that target transient populations: AeroClinic, which operates in airports, and Roadside Med, which operates in Pilot Travel centers that are located next to highways. These clinics serve employees of their respective retail hubs in addition to travelers. We verified the list of companies with 2 experts on the retail clinic industry: MaryKate Scott, an independent consultant, and Caroline Ridgeway from the Convenient Care Association, which is a lobbying organization for the retail clinic industry. We obtained the addresses of all clinics from the retail clinic companies' web sites between June and August 2008.

\section{Mapping of Retail Clinics}

Using geospatial imaging software (ArcInfo version 9.3, ESRI, Inc., Redlands, CA) we mapped the location of each clinic. Many retail clinics have opened in newly built neighborhoods that do not map directly to an identified street in the ESRI street database, which is several years old. For 28\% of clinics, we used Google maps to correct misspelled addresses, identify alternate city names or zip codes, or isolate the closest address of a location that was able to mapped. If we used the closest address that was able to be mapped, it was within 1 to 2 blocks of the actual retail clinic location.

\section{Creating Retail Clinic Catchment Areas}

We defined the catchment area around each retail clinic as a 5 -minute driving distance in each direction. The catchment algorithm relies on roadbased travel to define the point boundaries in every direction and then makes linear connections between these point boundaries to create a boundary loop. The travel time calculated incorporates average driving speed on the type of road (eg, faster speeds on highways), but does not incorporate typical levels of traffic. We chose a 5-minute driving distance to define the minimum size of catchment areas because previous research estimates 5 minutes as the time persons are willing to travel to some retail stores. ${ }^{24}$ We looked at a 10 -minute driving distance catchment area, as well, to test the sensitivity of our analyses.

\section{Defining Population Within and Outside Retail Clinic Catchment Areas}

We compared the sociodemographic characteristics of the populations within and outside the retail clinic catchment areas. Because the vast majority of retail clinics were in urban areas, our analyses focus on only the US urban population. Urban areas have been defined by the Census Bureau ${ }^{25}$ and include regions with a population greater than 500 to 1000 people per square mile or adjoining areas. Using ArcGIS (ESRI, Inc.) we selected all urban census blocks whose centroids lay within a retail clinic catchment area. Census blocks are the smallest increment of census data; there were approximately 8.5 million census blocks in the 2000 census. $^{25}$ They contain limited aggregated information from a $100 \%$ survey of the population and average 33 people per block. Blocks are aggregated into block groups, which are aggregated into census tracts, which are aggregated into counties, which are aggregated into states. After evaluating several possible aerial interpolation methods, we felt the census 
block centroid analysis to be the most logical for our purposes given the granularity of the data.

We acquired US Census data at the block level for race, ethnicity, age, and sex from 2000 (the most recent detailed data available). Because income, education, and urban population data are not available only at the block level, we imputed these data from the census tract. For example, if $22 \%$ of the tract had a college education, we assumed that $22 \%$ of the population of each block in that tract had a college education. On average, 120 blocks make up census tracts, which contain an average of 4000 people. To our knowledge, the most granular health insurance data are available at the county level. We obtained data about health insurance rates at the county level in 2005 from the Census Bureau's Small Area Health Insurance Estimates division and applied this data to the block level.

We created a multivariate model to determine characteristics of a census block that were associated with the census block being within a 5-minute retail clinic catchment area. The unit of analysis was the census block ( $\mathrm{n}=2,379,547)$. We set the outcome variable as a binary "within" or "outside of" a retail clinic catchment area and used the census block characteristics listed above (eg, percentage of census block that was nonwhite race) as predictor variables. We limited our analysis to urban census blocks with $\geq 10$ residents to ensure a stable estimate of census characteristics. Because of collinearity with median income, we did not include 2 variables in the model: percentage of residents with a college education and percentage of residents below the poverty line. Insurance rates were not included because they were pulled from the county level. Because of a nonlinear relationship between predictor and outcome variables, we chose to divide the census block characteristics into quartiles. Many of the predictor variables were collected at the level of the census tract, so we accounted for clustering using proc surveylogistic software (version 9.1, SAS Institute, Cary, NC). We conducted a sensitivity analysis using a binary outcome variable of "within" or "outside of" a 10minute catchment area.

We used geospatial imaging software to determine the fraction of retail clinics located in primary care health professional shortage areas (HPSAs). HPSA geographic boundaries are defined by the Health Resources and Services Administration. ${ }^{26}$

\section{Results}

As of August 2008, 42 different clinic companies operated 982 retail clinics in the United States (Table 1). Although more than 40 operators run retail clinics, the 5 largest (MinuteClinic, TakeCare, Little Clinic, TargetClinic, and Redi-Clinic) run $82 \%$ of the clinics. Clinics were located most frequently in urban areas (88.2\% of clinics) and $99.1 \%$ of the population that lives within 5 minutes of a retail clinic lives in an urban area. Across the nation, $12.5 \%$ of the clinics are located in an HPSA whereas $20.9 \%$ of the general US population lives in an HPSA. ${ }^{27}$

Compared with other urban residents, the population that lives within a 5 -minute retail clinic catchment area has a higher median household income $(\$ 52,943$ vs $\$ 46,080)$, is better educated ( $32.6 \%$ vs $24.9 \%$ with a college education), is less likely to live below the poverty line $(10.2 \%$ vs $12.6 \%)$, and has a higher proportion of the population that is Hispanic or Latino (17.6\% vs $15.4 \%)$ (Table 2). They have similar rates of being uninsured $(17.7 \%$ vs $17.0 \%)$ and there were no notable differences in age or sex. The demographic comparison was substantively the same when we used a 10-minute catchment area.

We created a multivariate model to determine characteristics of a census block that were associated with being within a 5 -minute retail clinic catchment area. The characteristic with the strongest association was median household income. Compared to census blocks with a median household income $<\$ 31,781$, census blocks where the median income was $\geq \$ 54,779$ were more likely (odds ratio, 3.63; 95\% CI, 3.26-4.05) to be within a 5 -minute catchment area (Table 3 ). Because of the large number of census blocks ( $>2$ million) all other variables had statistically significant associations, but the magnitude of the associations was relatively smaller (odds ratio, $<2$ ).

\section{Discussion}

Supporters of the retail clinic model have argued that its growth could improve access to care in general and in particular for the underserved, including the poor and those with little access to primary care physicians. We find that retail clinics are not preferentially located in communities with these demographics. A relatively small fraction of clinics are located in an HPSA, and the income of 
Table 1. Retail Clinic Companies Operating Clinics as of August 2008

\begin{tabular}{|c|c|}
\hline Retail Clinic Operator & $\begin{array}{c}\text { Total Clinics } \\
\text { as of August } \\
2008(\mathrm{n})\end{array}$ \\
\hline MinuteClinic & 514 \\
\hline Take-Care Health Clinics & 176 \\
\hline The Little Clinic & 60 \\
\hline Redi-Clinic & 36 \\
\hline Target Clinic & 24 \\
\hline Aurora QuickCare & 19 \\
\hline NOW Express Care & 16 \\
\hline QuickHealth & 16 \\
\hline Solantic & 16 \\
\hline Lindora Health Clinics & 9 \\
\hline Alegent Quickcare & 6 \\
\hline QuickClinic & 6 \\
\hline Sutter Express & 6 \\
\hline Bellin Health Fast Care & 5 \\
\hline Curaquick Clinic & 5 \\
\hline $\begin{array}{l}\text { Geisinger - CareWorks Convenient } \\
\text { Healthcare }\end{array}$ & 5 \\
\hline Intermountain ExpressCare & 5 \\
\hline St. Alphonsus Express Care & 5 \\
\hline Fairview ExpressCare & 4 \\
\hline MediMin & 4 \\
\hline MedPoint Express & 4 \\
\hline Mercy QuickCare & 4 \\
\hline ExpressHealth & 3 \\
\hline Family QuickCare & 3 \\
\hline Gunderson Lutheran ExpressCare & 3 \\
\hline RoadSide Med & 3 \\
\hline ValuClinic & 3 \\
\hline Aero Clinic & 2 \\
\hline DR Walk-In & 2 \\
\hline ExpressAid & 2 \\
\hline HealthPartners Health Station & 2 \\
\hline HealthRite & 2 \\
\hline OMC FastCare & 2 \\
\hline Premier ExpressCare & 2 \\
\hline ALMC ExpressCare & 1 \\
\hline CMC-Express & 1 \\
\hline ExpressCare & 1 \\
\hline Mayo Express Care & 1 \\
\hline MedAisle Express Care & 1 \\
\hline Mercy Express Care Center & 1 \\
\hline Redi-Care & 1 \\
\hline St. Lukes Qcare & 1 \\
\hline Total & 982 \\
\hline
\end{tabular}

census blocks within 5 minutes of a retail clinic was higher than that of the rest of the urban population.

How can these findings influence the continuing debate about retail clinics? First, it should dispel the notion that retail clinic companies are specifically targeting the underserved. Rather, except for the differences in income and education, the urban residents that live within a retail clinic catchment area are similar to the urban population as a whole. This may not be surprising. Retail clinics are most commonly run by for-profit companies who want to reach as broad a segment of the whole population as possible. It is also important to note that primary care physicians' offices are often preferentially located in higher-income areas. ${ }^{28}$ Second, the vast majority of retail clinics are in urban areas. This might make sense from a business perspective as companies try to reach as many clients as possible, but rural areas are most in need of new care options.

There are several key limitations to our analyses. The decision about where retail clinic companies place a retail clinic is likely influenced by variables outside our analysis, such as available partner retail stores (eg, availability of a Walgreens in the area), suitable store layout for a retail clinic (eg, a corner of the store with available plumbing), and store foot traffic. We used 5-minute and 10-minute driving distances to define retail clinic catchment areas, but this was not informed by previous access to care literature. This literature has generally focused on other types of situations, such as how distance to a radiation oncologist might impact a patient's decision to undergo breast-conserving surgery, and therefore was not applicable to retail clinics. ${ }^{29}$ Therefore, we used data about typical travel times to a grocery store as a proxy. ${ }^{24} \mathrm{We}$ recognize that patients vary in the distance they are willing to travel; other factors such as physical geography and personal driving patterns will influence who is willing to drive to a clinic. For example, patients in rural areas are probably willing to drive a longer distance. As noted above, we looked at the entire population within a catchment area, recognizing that this population is the "possible clientele" rather than the "probable clientele" of the retail clinic. For example, an elderly patient who has a strong relationship with her primary care physician may live in the catchment area but will not likely go to the retail clinic. 


\begin{tabular}{|c|c|c|c|}
\hline & \multicolumn{3}{|c|}{ Urban Population (millions) } \\
\hline & $\begin{array}{c}\text { Total } \\
(\mathrm{n}=222.4)\end{array}$ & $\begin{array}{c}\text { Within } \\
(\mathrm{n}=29.7)\end{array}$ & $\begin{array}{c}\text { Outside } \\
(\mathrm{n}=192.7)\end{array}$ \\
\hline \multicolumn{4}{|l|}{ Sex } \\
\hline Male & $108.5(48.8)$ & $14.5(48.8)$ & $94.0(48.8)$ \\
\hline Female & $113.9(51.2)$ & $15.2(51.2)$ & $98.7(51.2)$ \\
\hline \multicolumn{4}{|l|}{ Race } \\
\hline White & $159.5(71.7)$ & $21.6(72.7)$ & $137.9(71.6)$ \\
\hline Black or African American & $30.7(13.8)$ & $3.5(11.8)$ & $27.2(14.1)$ \\
\hline Other & $62.9(28.3)$ & $8.1(27.3)$ & $54.8(28.4)$ \\
\hline \multicolumn{4}{|l|}{ Ethnicity } \\
\hline Not Hispanic or Latino & $187.5(84.3)$ & $24.5(82.4)$ & $163.0(84.6)$ \\
\hline Hispanic or Latino & $34.9(15.7)$ & $5.2(17.6)$ & $29.7(15.4)$ \\
\hline \multicolumn{4}{|l|}{ Age (years) } \\
\hline$<5$ & $15.5(7.0)$ & $2.0(6.7)$ & $13.5(7.0)$ \\
\hline $5-17$ & $41.4(18.6)$ & $5.1(17.2)$ & $36.3(18.8)$ \\
\hline $18-44$ & $90.8(40.9)$ & $12.7(42.9)$ & $78.1(40.5)$ \\
\hline $45-64$ & $47.3(21.3)$ & $6.3(21.2)$ & $41.0(21.3)$ \\
\hline$\geq 65$ & $27.3(12.3)$ & $3.6(12.0)$ & $23.7(12.3)$ \\
\hline \multicolumn{4}{|l|}{ Education } \\
\hline$<$ High school & $44.0(19.8)$ & $5.0(17.0)$ & $39.0(20.2)$ \\
\hline High school & $59.1(26.6)$ & $6.8(22.9)$ & $52.3(27.2)$ \\
\hline Some college & $61.6(27.7)$ & $8.1(27.4)$ & $53.5(27.7)$ \\
\hline College graduate & $57.6(25.9)$ & $9.7(32.6)$ & $47.9(24.9)$ \\
\hline \multicolumn{4}{|l|}{ Insurance ${ }^{*}$} \\
\hline Percent uninsured & $38.0(17.1)$ & $5.3(17.7)$ & $32.8(17.0)$ \\
\hline \multicolumn{4}{|l|}{ Income } \\
\hline Below poverty & $27.3(12.3)$ & $3.0(10.2)$ & $24.3(12.6)$ \\
\hline Median household income (\$) & 46,983 & 52,849 & 46,080 \\
\hline
\end{tabular}

Based on Census data from 2000. This table focuses only on the urban population because the vast majority of retail clinics are located in urban areas. Retail clinic catchment areas were defined as those census blocks within a 5-minute driving distance around any clinic. Data provided as $\mathrm{n}(\%)$, except for median household income.

*Insurance rates were obtained at the county level and then applied to the census tract.

There were several analytic issues related to using census data that introduced some error in our results. Several sociodemographic characteristics in our analysis were not available at the census-block level. For example, health insurance data are available only at the county level. To include these data, we chose to impute available county-level data about insurance rates to the census block level. Because counties can encompass areas much larger than a typical retail clinic catchment area, we have a limited ability to detect differences in insurance rates of those within and outside a retail clinic catchment area. Therefore, insurance-related results should be interpreted with caution. Previous research has found that retail clinics attract patients who are less likely to use insurance to pay for a visit than patients who visit a physician. ${ }^{1}$ It might be that those without insurance might be preferentially seeking retail clinics for care. Lastly, by necessity we used census data from 2000 whereas clinic addresses and HPSA boundaries were from 2008. All of these census-related methodological issues introduce some error in our results, but whether they bias our findings is unclear.

\section{Conclusions}

Retail clinics are a rapidly growing segment of the US health care system that has garnered significant interest and controversy. We believe our study represents one of the first in the peer-reviewed literature to describe on a national scale who can visit a retail clinic. The communities surrounding retail clinics are, on average, wealthier and better edu- 
Table 3. Census Tract Characteristics Associated With Being in a Retail Clinic Catchment Area (Multivariate Model)

\begin{tabular}{|c|c|}
\hline Census Block Characteristics & Odds Ratio $(95 \% \mathrm{CI})$ \\
\hline \multicolumn{2}{|l|}{ Children/adolescents ( $<18$ years old) } \\
\hline Quartile $1(<17.9 \%)$ & $1.64(1.57-1.71)$ \\
\hline Quartile $2(\geq 17.9 \%$ and $<25.3 \%)$ & $1.28(1.24-1.32)$ \\
\hline Quartile 3 ( $\geq 25.3 \%$ and $<32.5 \%)$ & $1.14(1.12-1.17)$ \\
\hline \multicolumn{2}{|l|}{ Quartile 4 ( $\geq 32.5 \%)$ Reference group } \\
\hline \multicolumn{2}{|l|}{ Elderly (older than 65 years) } \\
\hline Quartile $1(<5.4 \%)$ & $1.23(1.18-1.28)$ \\
\hline Quartile $2(\geq 5.4 \%$ and $<11.1 \%)$ & $1.19(1.15-1.23)$ \\
\hline Quartile $3(\geq 11.1 \%$ and $<19.0 \%)$ & $1.11(1.09-1.14)$ \\
\hline Quartile $4(\geq 19.0 \%)$ & Reference group \\
\hline \multicolumn{2}{|l|}{ Nonwhite* } \\
\hline Quartile $1(0 \%)$ & Reference group \\
\hline Quartile $2(\geq 0 \%$ and $<10.7 \%)$ & $1.28(1.25-1.32)$ \\
\hline Quartile 3 ( $\geq 10.7 \%$ and $<34.6 \%$ ) & $1.38(1.33-1.43)$ \\
\hline Quartile 4 ( $\geq 34.6 \%)$ & $1.36(1.28-1.45)$ \\
\hline \multicolumn{2}{|l|}{ Hispanic* } \\
\hline Group $1(0 \%)$ & Reference group \\
\hline Group $2(\geq 0 \%$ and $<12.9 \%)$ & $1.30(1.27-1.33)$ \\
\hline Group 3 ( $\geq 12.9 \%)$ & $1.45(1.37-1.52)$ \\
\hline \multicolumn{2}{|l|}{ Male } \\
\hline Quartile $1(<44.4 \%)$ & Reference group \\
\hline Quartile $2(\geq 44.4 \%$ and $<48.6 \%)$ & $1.03(1.01-1.04)$ \\
\hline Quartile 3 ( $\geq 48.6 \%$ and $<52.6 \%$ ) & $1.03(1.01-1.04)$ \\
\hline Quartile $4(\geq 52.6 \%)$ & $1.05(1.03-1.07)$ \\
\hline \multicolumn{2}{|l|}{ Median household income } \\
\hline Quartile $1(<\$ 30,781)$ & Reference group \\
\hline Quartile $2(\geq \$ 30,781$ and $<\$ 40,391)$ & $1.52(1.36-1.69)$ \\
\hline Quartile $3(\geq \$ 40,391$ and $<\$ 54,779)$ & $2.44(2.20-2.71)$ \\
\hline Quartile $4(\geq \$ 54,779)$ & $3.63(3.26-4.05)$ \\
\hline
\end{tabular}

This table focuses only on the urban population and defines retail clinic catchment area based on a 5 -minute driving distance.

*We could not define 4 quartiles for these variables because of skew (a large number of census blocks with $0 \%$ nonwhite or Hispanic population). For the Hispanic percentage variable we divided the census blocks into 3 groups. For the nonwhite percentage variable we divided the census blocks into 4 groups, but the quartile 1 group had slightly more than a quarter of the census blocks whereas the quartile 2 group had slightly less than a quarter.

cated than the rest of the nation. These results can help inform the ongoing policy debate about the potential harms and benefits of the retail clinic model.

\section{References}

1. Mehrotra A, Wang MC, Lave JR, Adams JL, McGlynn EA. Retail clinics, primary care physi- cians, and emergency departments: a comparison of patients' visits. Health Aff 2008;27:1272-82.

2. Laws M, Scott MK. The emergence of retail-based clinics in the United States: early observations. Health Aff 2008;27:1293-8.

3. Starz TW. Quick health care is not the same as primary care. Pittsburgh Post-Gazette, 1 November 2006. Available at http://www.post-gazette.com/pg/ 06305/734460-109.stm. Accessed 12 November 2009.

4. Japsen B. AMA takes on retail clinics. Chicago Tribune, 2007 June 25. Available at http://archives. chicagotribune.com/2007/jun/25/business/chi-clinics_ bizjun25. Accessed 12 November 2009.

5. Steenhuysen J, Reuters. AMA to seek probe of retail health clinics [25 July 2007]. Available at www.reuters. com/article/healthNews/idUSN2531074620070626. Accessed 28 October 2009.

6. O'Keefe L, American Academy of Pediatrics. Academy takes aim at retail-based clinics. AAP News 2006:9;1. Available at aapnews.aappublications.org/ cgi/content/citation/27/11/1. Accessed 28 October 2009.

7. American Academy of Family Physicians. Retail health clinics. Desired attributes of retail health clinics. Available at www.aafp.org/online/en/home/ policy/policies/r/retailhealthclinics.html. Accessed 28 October 2009.

8. Retail-Based Clinic Policy Work Group, American Academy of Pediatrics. AAP principles concerning retail-based clinics. Pediatrics 2006;118:2561-2.

9. Bohmer R. The rise of in-store clinics-threat or opportunity? N Engl J Med 2007;356:765-8.

10. State of California. The Governor's health care plan. The Health Care Security and Cost Reduction Act. Available at http://www.fixourhealthcare.ca.gov/ plan. Accessed 31 October 2008.

11. Commonwealth of Pennsylvania. First pieces of Governor Rendell's "Prescription for Pennsylvania" signed into law [20 July 2007]. Available at www. state.pa.us/papower/cwp/view.asp?A=11\&Q=465657. Accessed 28 October 2009.

12. McCain J, The American Presidency Project. Remarks on health care on day two of the "Call to Action Tour" at the University of South Florida, Lee Moffitt Cancer Center \& Research Institute in Tampa, Florida [29 April 2008]. Available at www. presidency.ucsb.edu/ws/index.php?pid=77195. Accessed 28 October 2009.

13. Gallegos A. Retail medicine: the cure for healthcare disparities? J Healthc Manag 2007;52:227-34.

14. Takach M, Witgert K, National Academy for State Health Policy. Analysis of state regulations and policies governing the operation and licensure of retail clinics [February 2009]. Available at www.nashp.org/ files/RetailClinics.pdf. Accessed 28 October 2009.

15. Harris Interactive. Many agree on potential benefits of onsite clinics in major retail Stores. Available at www.marketresearchworld.net/index.php?option = 
com_content\&task=view $\& \mathrm{id}=354 \&$ Itemid $=77$. Accessed 28 October 2009.

16. Davis MM. More children expected to seek care at retail clinics. National Poll on Children's Health 2007;1(1). Available at http://www.med.umich.edu/ mott/research/CBH\%20Poll/NPCH\%20vol\%201 \%20issue \%201\%20April\%2022\%20FINAL_files/ Child\%20Health\%20Poll\%20Report\%20vol1\%20 issue1\%20041807.pdf. Accessed 12 November 2009.

17. Rohrer JE, Yapuncich KM, Adamson SC, Angstman $\mathrm{KB}$. Do retail clinics increase early return visits for pediatric patients? J Am Board Fam Med 2008;21: 475-6.

18. Harris Interactive. Most adults satisfied with care at retail-based health clinics [11 April 2007]. Available at www.harrisinteractive.com/news/allnewsbydate. asp? NewsID = 1201. Accessed 28 October 2009.

19. University of Michigan Health System. C. S. Mott Children's Hospital National Poll on Children's Health. Available at www.med.umich.edu/mott/ npch. Accessed 28 October 2009.

20. Keckley PH, Underwood HR, Ghandi M, Deloitte Center for Health Solutions. Retail clinics: facts, trends, and implications. Available at www.deloitte. com/dtt/cda/doc/content/us_chs_RetailClinics_230708. pdf. Accessed 28 October 2009.

21. Thygeson M, Van Vorst KA, Maciosek MV, Solberg $\mathrm{L}$. Use and costs of care in retail clinics versus traditional care sites. Health Aff 2008;27:1283-92.

22. Scott MK, California Healthcare Foundation. Health care in the express lane: retail clinics go mainstream [September 2007]. Available at www. chcf.org/topics/view.cfm?itemID =133464. Accessed 28 October 2009.

23. Convenient Care Association. Clinic locations. Available at www.ccaclinics.org. Accessed 28 October 2009.

24. Dunkley B, Helling A, Sawicki DS. Accessibility versus scale: examining the tradeoffs in grocery stores. JEPR 2004;23:387-401.

25. US Census Bureau. [Homepage] Available at http:// www.census.gov. Accessed 4 November 2008.

26. Health Resources and Services Administration. HRSA Geospatial Data Warehouse. Connecting to HGDW map data with ArcExplorer Java edition. Available at http://datawarehouse.hrsa.gov/ConnectWithArcExplorer.aspx. Accessed 4 November 2008.

27. Health Resources and Service Administration, US Department of Health and Human Services. Shortage Designation: HPSAs, MUAs, and MUPs. Available at http://bhpr.hrsa.gov/shortage/. Accessed 28 October 2009.

28. Guagliardo MF, Ronzio CR, Cheung I, Chacko E, Joseph JG. Physician accessibility: an urban case study of pediatric providers. Health Place 2004;10: 273-83.

29. Athas $W$, Adams-Cameron $M$, Hunt $W$, Amir-Fazli A, Key C. Travel distance to radiation therapy and receipt of radiotherapy following breast-conserving surgery. J Natl Cancer Inst 2000;92:269-71. 